\title{
Implementation of Learning Model Map Concept with Inquiry Strategy in an Effort to Train High- Order Thinking Skills of Chemistry Education Students
}

\author{
Ismono $^{1}$, Sri Poedjiastoeti ${ }^{2}$, Suyatno Suyoto ${ }^{3}$ \\ Chemistry Department \\ Universitas Negeri Surabaya \\ Surabaya, Indonesia \\ 1ismono@unesa.ac.id
}

\begin{abstract}
Higher order thinking skills (HOTs) are needed by the students of chemistry education, because they will become teachers who will be able to teach HOTs to the students. This research is the application of concept map learning models with inquiry strategies to train higher order thinking skills of chemical education students. This study aims to determine the impact of training from the application of concept map learning models to inquiry strategies to increase gain scores and retention of higher order thinking skills. The subjects of the study of chemical education students were 66 students who were divided into two classes, namely PKA class (34 students) and PKB (32 students). improvement in learning outcomes is calculated using an increase in score gains while the retention test uses t test (spss-16). The results of the study are the increase in score gains in: (a) analytical skills for PKA (0.56) and PKB (0.58) are medium; (b) evaluation capability for PKA (0.51) and PKB (0.54) are medium; (c) synthesis capability PKA (0.50) and PKB (0.54) are medium. Based on the $t$ test $(0,05)$, there was no significant difference in the increase in PKA and PKB classes in higher order thinking skills, sig ( 2 tailed) analysis 0.627 , evaluation 0.465 , and synthesis 0.117 . The results of a retention test obtained a score (2-tailed) Analysis of 0.778; Evaluation 0.501; Synthesis of 0.321, so there is no significant difference between the posttest test and retention test. above $90 \%$ of students responded positively to the concept map learning model with inquiry strategy.
\end{abstract}

Keywords - high order thinking skills; concept map; inquiry strategy

\section{INTRODUCTION}

Education in Indonesia today are faced with some very strategic issues, among others: (a) learning should involve learners actively in finding and building knowledge through higher order thinking and inquiry, problem solving and collaborative work and collaborative learning [1]; (b) students must have the ability to think critically, be able to apply conceptual knowledge and procedural to solve problems, and explain the interrelationship between concepts in a subject matter that is effectively and creatively $[2,3]$.
Based on these strategy issues, then in studying science (chemistry), the chemistry teacher and candidates of teacher must have the ability to higher order thinking skills, inquiry, and understand the concepts of chemistry that will be taught in depth and strongly, which in turn they will be able to teach their students.

Numerous reports support the view that the interplay between studying the chemistry concepts with inquiry and higher order thinking is a source of difficulty for many chemistry learners: (a) studying the chemistry concepts (concept in organic chemistry) is often perceived as a difficult subject, because the chemical concepts (organic) are generally abstract for that higher order thinking skills are needed to get the right understanding. rote learning (recall) is a learning that is relatively difficult to use in learning abstract concepts of chemistry. The researchers found evidence that when students use rote learning, it will experience a misunderstanding understand chemistry concepts. So, for that it is necessary to use meaningful learning because learning is suitable for studying chemistry (organic) [4, 6]; (b) chemical content (organic chemistry) generally has many abstract concepts, hierarchically organized, and often between concepts experience relationships. Meaningful learning and high order thinking skills are suitable for teaching to concepts of organic chemical [5]; (c) to learn of chemistry (organic chemistry), requires a lot of investigation, high-level thinking skills, and understanding of concepts, because chemistry contains many abstract concepts, the concepts are arranged hierarchically, and generally between concepts have relationships [7]; (d) the acquisition of knowledge isomers (structural and stereo chemical) is very difficult and concepts confuse learners $[8,9$, 10]; (e) in order to improve students' understanding of conceptual knowledge can use learning strategies that engage students in higher order thinking skill through of inquiry activities, collaboration learning, discussions, brainstorming, argument, and simulation [11]. Teaching strategies that can be used may be learning and work collaboratively in both the inquiry and discussions, brainstorming, simulation, and implementation [12]; (f) the presentation of knowledge of 
concepts of students with concept mapping strategy can be enhances their performance and academic achievement in organic chemistry and retention of the knowledge [13]; (g)_the concept maps (Cmaps) and inquiry are valuable tools for assessing the effectiveness of the conceptual changes provoked by engagement activities of students and inquiry done of teaching materials at the classroom [14,15]; (h) Angelo and Cross indicate that the use of concept maps develop students' abilities to draw inferences from observations, analyze, evaluate, synthesize and integrate information. Concept mapping also enables students to make meaning out of information, make judgments and develop informed opinions $[16,17]$.

Based on the opinions of some of the experts above, then to learn to teach organic chemistry that is rich in abstract concepts, organized hierarchically, and often there is a connection between concepts, so meaningful learning is needed with the strategy of inquiry and the ability for higher-order thinking skills. The learning process in studying chemistry should use an inquiry strategy with collaborative learning to engage students actively in observing, analyzing, synthesizing and evaluating concepts, discussing, and brainstorming, so that they will be able to provide concrete experiences and meaningful learning. Thus, it is necessary to apply learning that can teach students to carry out investigations and higher-order thinking skills (analysis, evaluation, and synthesis), so that it is expected to improve learning achievement, high order thinking skills, communicate, and can have a longer retention time. maintain concepts in cognitive long-term memory.

\section{THEORETICAL REVIEW}

Based on this, the learning model that will be applied in this study is a concept map model with inquiry strategy. This model will actively engage students to investigate and discover concepts, identify and analyze important concepts through discussion, brainstorming, collaboration activities. The process of concept synthesis is carried out through assimilation and accommodation processes $[18,19,20,21]$. The learning models of concept map with inquiry strategies also teach students to analysis. evaluate important concepts and synthesize (high order thinking) the relationship between the concepts. [22, 23].

Learning theory of learning that can be used in learning concept that has characteristics that are abstract concepts, organized hierarchically, and the relationship between the concepts of having a theory of meaningful learning [24. (25]. Meaningful learning theory has three principles: (1) when the learner can visualize these concepts and classifying it in the cognitive structure of learners; (2) classification of the concept starts from the concept of the most general to the most specific; (3) the readiness of learners that includes the knowledge that learners have today and receive knowledge/new concepts and linking with prior of knowledge [20].

Based on the theory of meaningful learning that the concepts are arranged hierarchically and inter-concept has can be used in learning concept map (CM). CM is the visualization of relationships between concepts in the form of twodimensional graphical representations and concepts are represented by rectangles or circles. The linkage between two or more concepts will be connected with the line of arrows $(\rightarrow$ labeled conjunctive) called with a proposition that meaningful relationships between concepts [26]. Learning of concept map suitable for use on the knowledge they have the characteristics of a declarative (conceptual) and procedural. Declarative knowledge is knowledge that requires explanation; whereas procedural knowledge is organized procedures such steps hierarchically organize concepts. The steps in preparing a concept map requires investigation (inquiry) capabilities, the invention of the concept contained in teaching materials and higher order thinking skills [27]. The higher order thinking skills include of analyzing, evaluating and synthesizing [28]. Vygotsky states there are four principles of constructivist learning theory underlying concept mapping, namely: (1) students to actively construct knowledge through relationships between concepts/ideas with prior of knowledge; (2) learners will personally create meaning through analyzing and synthesizing the experience so that new understanding can be constructed; (3) learning activities should foster the integration of thoughts, feelings and activities (actions) that help learners in the development process of meaning; (4) learning is a social activity that can be enhanced through learning and collaborative investigation between facilitators and learners or between learners with other learners. [29].

Piaget (1964) sees cognitive development as.... while at the formal operational stage (12 years and above), they can engage in formal thinking as well as abstraction. Piaget believed that the process of thinking and the intellectual development has also two on-going processes: assimilation and accommodation. There is assimilation when a child responds to a new event in a way that is consistent with an existing schema. There is accommodation when a child either modifies an existing schema or forms an entirely new schema to deal with a new object or event [30]. The model Piaget developed in stage three, he argued that intelligence develops in a series of stages that are related to age and are progressive because one stage must be accomplished before the next can occur. For each stage of development, the child forms a view of reality for that age period. At the next stage, the child must keep up with earlier level of mental abilities to reconstruct concepts. Piaget conceived intellectual development as an upward expanding spiral in which children must constantly reconstruct the ideas formed at earlier levels with new, higher order concepts acquired at the next level [31]. Based on the theory of Piaget, the teaching learning based on concept map is an appropriate learning in developing the ability to construct and relate the concept of linkages between concepts has a hierarchical structure. Piaget believed that learners who have over 12 years of age have been able to be invited to formal thinking to understand concepts such abstract concepts contained in the science of learning materials, such as concept isomer of organic chemistry.

A concept map is used to help students organize and represent knowledge of a subject. Concept maps begin with a main idea (or concept) and then branch out to show how that main idea can be broken down into specific topics. Concept mapping used as learning and teaching technique, concept mapping visually illustrates the relationships between concepts. 
Often represented in circles or boxes, concepts are linked by words and phrases that explain the connection between the concepts, helping students organize and structure their thoughts to further understand information and discover new relationships. Most concept maps represent a hierarchical structure, with the overall, broad concept first with connected sub-topics, more specific concepts [24, 25, 27].

Concept mapping is a powerful way for students to train of higher order thinking skills and to reach high levels of cognitive performance. A concept map is also not just a learning tool, but an ideal evaluation tool for educators measuring the growth of and assessing student learning. As students create concept maps, they reiterate ideas using their own words and help identify incorrect ideas and concepts; educators are able to see what students do not understand, providing an accurate, objective way to evaluate areas in which students do not yet grasp concepts fully.

Concept mapping serves several purposes for learners: (1) helping students brainstorm and generate new ideas; (b) encouraging students to discover new concepts and the propositions that connect them; (c) allowing students to more clearly communicate ideas, thoughts and information; (d) helping students integrate new concepts with older concepts; (e) enabling students to gain enhanced knowledge of any topic and evaluate the information. Learning of concept map with inquiry strategies can be done at level 3 [32], in which learners must investigate and find their own concepts (No condition) in content or topics under the guidance of teacher.

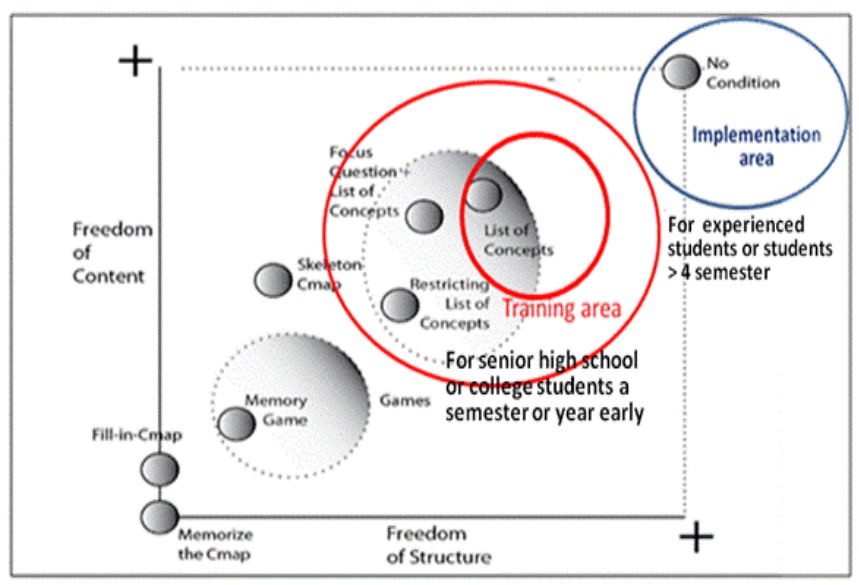

Fig. 1. The method used to implementation of learning model (adoption and adaptation from [31].

The means to training for the learners to understand the preparation of concept maps can be done on 2 levels (list of concepts), namely educators provide 15 to 20 key concepts, and then learners to construct of concept maps-based hierarchy concepts. Whereas implementation of learning model of concept with inquiry strategy for the training of higher order thinking skills used concept maps level 3 "no conditions". Students in the learned process of concept map "no conditional" will be identify of the key concepts, analyze, evaluate from handout and synthesis to create/building of hierarchy concept map. Evaluation at concept map level 3 (no condition) is used way of Markham, et.al, 1994 [33] as a result of the development of the rubric developed by Novak and Gowin [34], with a scoring rubric as follows: concept (1); preposition (1); linked (1); cross linked (10); level (5), and example of concept (1).

Based on strategic issues currently of developing learning and learning theory developed meaningful learning (Ausubel), theory of cognitive development and constructivist (Piaget and Vygotsky), information processing theory, and the concept map (Novak and Canas) above, it is necessary to develop innovative learning models. Learning to engage learners actively in the investigation, identification, analysis, synthesis, evaluation, discussion, brainstorming, communication, collaboration to understand, construction concepts, and has the ability to maintain an understanding of concepts (retention) is relatively long in structure learners cognitive learning model offered by the learning model of concept with inquiry strategy has five syntaxes; (Engagement, Assimilation-accommodation, Collaboration, Simulation, and implementation).

Engagement, students are actively involved in investigating urgent concepts in reading material. The results are written on student worksheet task 1. Accommodation-accommodation, students discuss with friends nearby or re-read teaching materials to improve and strengthen the concept. The results are written on student worksheet task 2.

Collaboration students collaborate to analyze and evaluate important concepts. The results are written on student worksheet task 3, 4, and 5.

Simulation, selected student groups simulate the results of their performance in front of other groups, the other groups provide criticism and suggestions for improving results. Based on input and suggestions, students improve their performance results. The results are written on the student worksheet task 6 . Implementation reflects the results of the learning process. Based on the learning experience and knowledge it has, students will use it to solve new problems. The results are written on student worksheet Task 7.

Model learning model of concept with inquiry strategy to teach subject matter of isomer and train higher order thinking skills also supported by teaching materials (syllabus, learning plan, student handbook, student activity sheets). The subject matter of the isomer is rich in abstract concepts, concepts are arranged hierarchically, and interrelationships between concepts are often related, for that reason higher order thinking skills and investigative skills (inquiry) are needed [35].

Prospective teacher or a chemistry teacher who studied chemistry (science) must have the ability in inquiry, higher order thinking skills, and understand the concepts of chemistry (organic chemistry) correctly, because they will be taught to students. In connection with the foregoing, This study aims will be to: (1) student learning activities, (2) student learning outcomes in terms of: (a) increasing acquisition scores with the category of minimal medium $(0.7\rangle(\langle\mathrm{g}\rangle)\rangle 0.3)$ [37] and (b) the ability to retain knowledge (retention) within 5 months posttest (95\% significance level); (3) student response to the implementation of the teaching model of concept map with the inquiry strategy. 


\section{EXPERIMENTAL DESIGN}

\section{A. Subject}

The subject research are 66 students to divided into two classes: PKA class (34 students) and PKB (32 students).

\section{B. Materials}

The materials used in this research among others: (1) student book of isomer; (2) student worksheet, (3) syllabus and lesson plan; (4) assessment and rubric and; (5) learning of media.

\section{Instrumentation}

Instruments used at this research are: (1) observation sheets of learning process; (2) observation sheet of student activity during the learning process; and (3) instrument for academic test (objective and subjective test) for pretest, posttest, and retention test.

\section{Procedure}

This research design is pretest - posttest design.

$$
\mathrm{O} 1-\mathrm{X}-\mathrm{O} 2-\mathrm{O} 3
$$

Where

$$
\begin{array}{ll}
\mathrm{O} 1=\text { pretest; } & \mathrm{O} 2=\text { posttest } \\
\mathrm{X}=\text { treatment; } & \mathrm{O} 3=\text { Retention test; }
\end{array}
$$

\section{RESULTS AND DISCUSSON}

Students activities during the learning process were observed by six observers using the observation instrument (which has been validated). Data on student activity can be seen in table I.

Based on the data in table I, it can be seen that student activities are in accordance with the syntax with learning concept maps with inquiry strategies, average student activity

\begin{tabular}{|c|c|c|c|c|c|c|c|c|c|c|c|c|c|c|c|c|c|}
\hline \multirow[t]{2}{*}{ 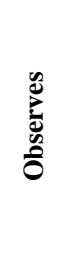 } & \multicolumn{3}{|c|}{ 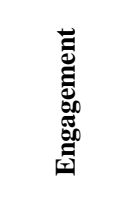 } & \multicolumn{2}{|c|}{ 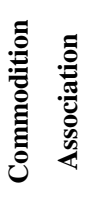 } & \multicolumn{6}{|c|}{ 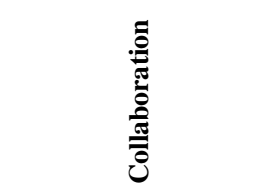 } & \multicolumn{3}{|c|}{ 离 } & \multicolumn{3}{|c|}{ 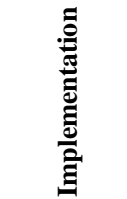 } \\
\hline & 1 & 2 & 3 & 4 & 5 & 6 & 7 & 8 & 9 & 10 & 11 & 12 & 13 & 14 & 15 & 16 & 17 \\
\hline 1 & 4 & 4 & 4 & 4 & 3 & 4 & 4 & 4 & 3 & 4 & 4 & 4 & 4 & 3 & 4 & 4 & 4 \\
\hline 2 & 4 & 4 & 4 & 4 & 4 & 4 & 4 & 4 & 4 & 4 & 4 & 4 & 4 & 4 & 3 & 4 & 4 \\
\hline 3 & 4 & 4 & 4 & 4 & 4 & 4 & 4 & 4 & 4 & 4 & 4 & 4 & 4 & 4 & 4 & 4 & 4 \\
\hline 4 & 4 & 4 & 4 & 4 & 4 & 4 & 4 & 4 & 4 & 4 & 4 & 4 & 4 & 4 & 4 & 4 & 4 \\
\hline 5 & 4 & 4 & 3 & 4 & 4 & 4 & 4 & 4 & 4 & 4 & 4 & 4 & 4 & 4 & 4 & 4 & 4 \\
\hline 6 & 4 & 4 & 4 & 4 & 4 & 4 & 4 & 4 & 4 & 3 & 4 & 4 & 4 & 4 & 4 & 4 & 4 \\
\hline Mean & 4 & 4 & $\begin{array}{l}m \\
\dot{m}\end{array}$ & 4 & $\begin{array}{l}m \\
\infty \\
\dot{m}\end{array}$ & 4 & 4 & 4 & $\begin{array}{l}\hat{\infty} \\
\dot{m}\end{array}$ & $\begin{array}{l}\infty \\
\dot{m}\end{array}$ & 4 & 4 & 4 & $\begin{array}{l}\infty \\
\dot{m}\end{array}$ & $\begin{array}{l}\infty \\
\dot{m}\end{array}$ & 4 & 4 \\
\hline
\end{tabular}
scores $>95 \%$.

\begin{tabular}{|c|c|c|c|c|c|c|c|c|c|c|c|c|c|c|c|c|c|}
\hline \multirow[t]{2}{*}{ 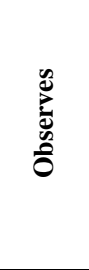 } & \multicolumn{3}{|c|}{ 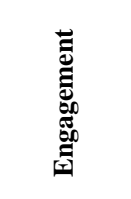 } & \multicolumn{2}{|c|}{ 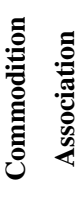 } & \multicolumn{6}{|c|}{ 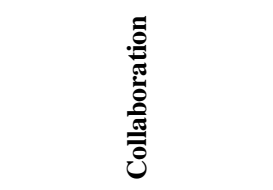 } & \multicolumn{3}{|c|}{ 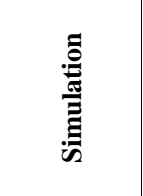 } & \multicolumn{3}{|c|}{ 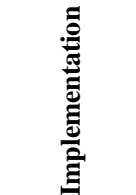 } \\
\hline & 1 & 2 & 3 & 4 & 5 & 6 & 7 & 8 & 9 & 10 & 11 & 12 & 13 & 14 & 15 & 16 & 17 \\
\hline$\%$ & \& & 8 & $\begin{array}{l}\infty \\
n \\
\alpha\end{array}$ & 8 & $\begin{array}{l}n \\
\ddot{\infty} \\
\infty\end{array}$ & 8 & 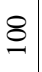 & 8 & $\begin{array}{l}\infty \\
\dot{n} \\
\end{array}$ & 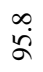 & 8 & 8 & 8 & $\begin{array}{l}\infty \\
\dot{a} \\
\dot{a}\end{array}$ & $\begin{array}{l}\infty \\
\dot{a} \\
\dot{a}\end{array}$ & 8 & 8 \\
\hline$\% \mathrm{oA}^{\mathrm{a}}$ & 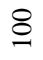 & 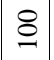 & $\triangleright$ & 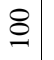 & $\triangleright$ & 8 & ¿ & 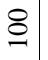 & $\infty$ & $\triangleright$ & $\triangleright$ & 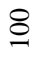 & 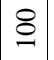 & $\triangleright$ & $\triangleright$ & 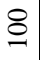 & 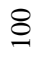 \\
\hline $\begin{array}{l}\mathrm{IoS}^{\mathrm{b}} \\
(\%)\end{array}$ & & 98.6 & & 97. & & & & 97. & & & & & 98.6 & & & 98.6 & \\
\hline
\end{tabular}

TABLE I. AVERAGE OF RESUlt STUDENT ACTIVITIES
Data from test results increase gain scores for PKA and PKB classes are presented in table II.

TABLE II. INCREASE OF GAINS SCORE FROM PKA AND PKB

\begin{tabular}{|c|c|c|c|}
\hline Class & Analysis & Evaluation & synthesis \\
\hline $\begin{array}{c}\text { A } \\
\text { (34 Students) }\end{array}$ & $\begin{array}{c}0.56 \\
\text { (medium) }\end{array}$ & $\begin{array}{c}0,51 \\
\text { (medium) }\end{array}$ & $\begin{array}{c}0.50 \\
\text { (medium) }\end{array}$ \\
\hline $\begin{array}{c}\text { B } \\
\text { (32 Students) }\end{array}$ & $\begin{array}{c}0.58 \\
\text { (medium) }\end{array}$ & $\begin{array}{c}0,54 \\
\text { (medium) }\end{array}$ & $\begin{array}{c}0,54 \\
\text { (medium) }\end{array}$ \\
\hline
\end{tabular}

Based on data in table II, it can be seen that the average gain gains in scores on high order thinking of abilities, analysis, evaluation, and synthesis in $\mathrm{A}$ and $\mathrm{B}$ classes with medium categories $(>0.50,0.30<(<$ gains $>)<0.70)$.

Test of average differences between pretest and posttest higher order thinking skills (analysis, evaluation, and synthesis at $\mathrm{A}$ and $\mathrm{B}$ classes used t-test (SPSS 16). The results of the average difference test between pretest and posttest in A and B classes can be seen in table III.

TABLE III. RESUlt OF PAORED SAMPEL TEST OF ABILITy HigheR ORDER THINKING SKILLS PKA AND PKB

\begin{tabular}{|l|c|c|c|c|c|}
\hline \multirow{2}{*}{$\begin{array}{c}\text { Cognitive } \\
\text { ability test }\end{array}$} & \multicolumn{4}{|c|}{ Result of pretest - posttest } & \multirow{2}{*}{ Description } \\
\cline { 2 - 5 } & $\boldsymbol{U 1}$ & $\boldsymbol{U} 2$ & $\boldsymbol{U} 2-\boldsymbol{U} 1$ & $\begin{array}{c}\text { Sig (2- } \\
\text { tailed })\end{array}$ & \\
\hline Analysis $^{\mathrm{a}}$ & 18.87 & 65.46 & 46.68 & 0.000 & difference \\
\hline Evaluation $^{\mathrm{a}}$ & 11.67 & 57.68 & 46.01 & 0.000 & difference \\
\hline Synthesis $^{\mathrm{a}}$ & 4.39 & 51.95 & 47.56 & 0.000 & difference \\
\hline Analysis $^{\mathrm{b}}$ & 16 & 65 & 49 & 0.000 & difference \\
\hline Evaluation $^{\mathrm{b}}$ & 13.14 & 61 & 47.86 & 0.000 & difference \\
\hline Synthesis $^{\mathrm{b}}$ & 12.4 & 59.0 & 46.6 & 0.000 & difference \\
\hline
\end{tabular}


Based on the $t$ test (SPSS 16) in table III it can be seen that there is a significant difference between pretest (U1) and posttest (U2) in PKA and PKB classes.

Test of the similarity of the average increase in gain scores between PKA class and PKB used t-test. The results of the average similarity analysis (t-test) can be seen in table IV.

TABLE IV. The Results of THE AVERAge SMILARATITy ANALYsis

\begin{tabular}{|l|l|c|c|c|c|c|}
\hline \multicolumn{2}{|l|}{} & $\boldsymbol{F}$ & Sig. & $\boldsymbol{t}$ & $\boldsymbol{d f}$ & $\begin{array}{c}\text { Sig. } \\
(\mathbf{2}- \\
\text { tailed })\end{array}$ \\
\hline $\begin{array}{l}\text { GAINSPKA } \\
\text { Analysis }\end{array}$ & $\begin{array}{l}\text { Equal variances } \\
\text { assumsed }\end{array}$ & 2.988 & .089 & -.489 & 64 & .627 \\
\hline $\begin{array}{l}\text { GAINSPKA } \\
\text { Evaluation }\end{array}$ & $\begin{array}{l}\text { Equal variances } \\
\text { assumed }\end{array}$ & .283 & .597 & -.735 & 64 & .465 \\
\hline $\begin{array}{l}\text { GAINSPKA } \\
\text { Synthesis }\end{array}$ & $\begin{array}{l}\text { Equal variances } \\
\text { assumed }\end{array}$ & .100 & .753 & -1.589 & 64 & .117 \\
\hline
\end{tabular}

Based on Table IV above it can be seen that: (a) the ability to analyze (sig. (2-tailed) $0.627>0.05$ ); (b) ability to evaluate sig. (2-tailed) of $0.465>0.05$; and (c) ability to synthesize, Sig. (2-tailed) of $0.117>0.05$. Thus, it can be stated that the increase in N-gains scores of both A and B classes does not have a significant difference, in the ability to analyze, evaluate, and synthesize.

Retention test is used to determine the ability of students to maintain their knowledge within 5 months after post-test. Retention test was done by comparing the results of the average final test with retention tests using the $t$ test with a significance level of 0.05 (SPSS 16). Based on the results of the draw, a retention test was conducted for B students (32 students). Based on the average difference test between the final test with retention test used t-test using SPSS 16 obtained results as shown in Table $\mathrm{V}$.

TABLE V. RESUlTS OF T-Test POSTTEST - RETENTION

\begin{tabular}{|c|c|c|}
\hline $\begin{array}{c}\text { High Order } \\
\text { thinking }\end{array}$ & Sig. (2-tailed) & $\begin{array}{c}\text { Description } \\
\text { t-test (>0.05) }\end{array}$ \\
\hline Analysis & 0.778 & Not difference \\
\hline Evaluation & 0.501 & Not difference \\
\hline Synthesis & 0.321 & Not difference \\
\hline
\end{tabular}

Based on Table $\mathrm{V}$, the three higher order thinking skills (analysis, evaluation, and synthesis) after being tested $\mathrm{t}$ were obtained by sig. (2-tailed) $>0.05$. Thus, it can be concluded that there is no significant difference between the average of the final test and the retention test.

Data of students' response was obtained using the questionnaire response instrument. Student questionnaire instruments were given to 30 students. The results of the student response questionnaire data can be seen in Figure 1.

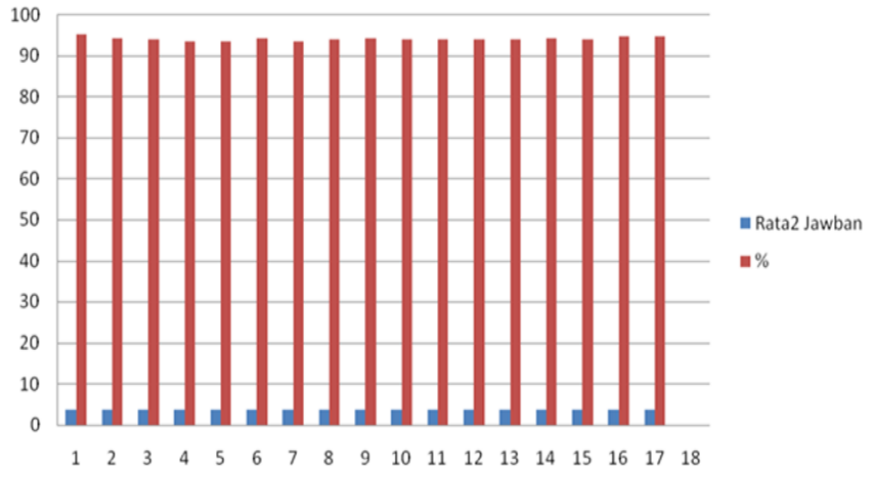

Fig. 2. Data of student response questionnaire.

Based on Figure 1 it appears that above $90 \%$ of students responded positively to the application of concept map learning models with inquiry strategy.

\section{CONCLUSION}

Based on the results of the data analysis above, it can be concluded that.

1. Above $95 \%$ of students have been actively involved in the learning process by using concept map learning models with inquiry strategies.

2. Teaching model of concept map learning with inquiry strategies can improve students' high school chemistry education thinking skills ( $\mathrm{A}$ and $\mathrm{B}$ ) with medium categories $(0.3<(<\mathrm{g}>)<07$.

3. Teaching model of concept map learning model with inquiry strategy can be maintain (retention) in higher order thinking skills and isomer subject matter.

4. Above 90 students responded positively to the implementation of the teaching model of concept map with inquiry strategy.

\section{RECOMMENDATION}

1. Educational students need to be trained in higher-order thinking skills, because they will later teach them to their students.

2. It is necessary to develop the application of concept map learning models with inquiry strategy on broader learning on subject matters that have the characteristics of abstract concepts, organized hierarchically, and between concepts having relationships.

\section{ACKNOWLEDGMENT}

Thank you profusely for prof. Dr. Sri Poedjiastoeti, M.Si and prof. Dr. Suyatno, M.Si, who has provided guidance for writing the results of this research. Thanks also to prof. Dr. Tukiran, M.Si, Dr, I Wayan Dasna, M.Ed, M.Sc., and Dr. Erman, M.Pd, who has validated the teaching materials and research instruments. Hopefully his good deeds can be rewarded by Allah SWT. 


\section{REFERENCES}

[1] H. Iskandar, Preparation of test Higher Order Thinking for senior high school, Directorate of Senior High School, The Ministry of National Education and Culture of the Republic of Indonesia, 2015.

[2] OECD, PISA 2012 Assessment and Analytical Framework Mathematics, Reading, Science, Problem Solving and Financial Literacy. Paris: OECD Publishing, 2013.

[3] L.H. Yusuf, The Paradigm of Learning in the 21st Century and Higher Education in Indonesia in the Era of Globalization, 2014. ISBN: 978602-8547-81-9.

[4] G.M. Bodner and D.S. Domin, "Mental models: the role of representations in problem solving in chemistry," Univ. Chem. Educ., vol. 4, pp. 24-30, 2000.

[5] K. Taber, Chemical misconceptions - prevention, diagnosis and cure: Theoretical background (vol. 1). London: Royal Society of Chemistry, 2002.

[6] U. Zoller and D. Pushkin, "Matching Higher-Order Cognitive Skills (HOCS) promotion goals with problem-based laboratory practice in a freshman organic chemistry course," Chem. Educ. Res. Pract., vol. 8, pp. 153-171, March 2007

[7] G. Sirhan, "Learning Difficulties in Chemistry: An Overview," Journal of Turkish Sciences Education, vol. 4, pp. 2-20, September 2007.

[8] M.S. Boukhechem, A. Dumon and M. Zouikri, "The acquisition of stereochemical knowledge by Algerian students intending to teach physical sciences," Chem. Educ. Res. Pract., vol. 12, pp. 331-343, 2011.

[9] N.I. Kurbanoglu, Y. Taskesenligil and M. Sozbilir, "Programmed instruction revisited: a study on teaching stereochemistry. Chemistry Education Research and Practice," vol. 7 (1), pp.13-21, December 2015.

[10] A. Zohar, Higher order thinking in science classrooms: Students learning and teachers' professional Development. Nether land: Kluwer Academic Publisher, 2004.

[11] T.S. Yen and S.H. Halili, "Effective Teaching of Higher Order Thinking (HOT) in Education," The Online Journal of Distance Education and eLearning, vol. 3, pp. 41-47, April 2015

[12] A.A. Arokoyu and C.O. Juliana, "Concept Mapping: An Instructional Strategy for Retention of Organic Chemistry concepts," International Journal of Scientific Research and Innovative Technology, vol. 1, pp. 50-57, October 2014.

[13] S. Hidi, and K.A. Renninger, The four-phase model of interest development. Educational. Psychologist, 42, (2), 111-127, 2006.

[14] H.L. Erickson, Concept-based teaching and learning. IBO Position Paper, 2012. www.ibo.org/.../inquiry-and-language-teaching-embracinga-c. Access on July 2016.

[15] D. Gabel, "Use of the Particle Nature of Matter in Developing Conceptual Understanding," Journal of Chemical Education, vol. 70(3), p. $193,1993$.

[16] M.I. Njoku and B.R. Bekinwari, "Concept mapping teaching strategy in a biology classroom for eradication of malaria," In O. Abonyi 54th annual conference proceeding of the Science Teachers' Association of Nigeria,. Ibadan: HEBN Publishers, 2013. (pp. 229-234)

[17] R.L. Solso, O.H. Maclin and M.K. Maclin, Cognitive psychology (8th Ed). Boston: Allyn \& Bacon, 2008.

[18] A. Woolfolk, Educational psychology (13th ed.). Boston, MA: Allyn \& Bacon, 2016.
[19] M. Safdar, A. Hussain, I. Shah and Q. Rifat, "Concept Maps: An Instructional Tool to Facilitate Meaningful Learning," European Journal of Educational, vol. 1, pp. 55-64, 2012.

[20] J.D. Herron, L.L. Cantu and R. Ward, "Problems Associated with Concept Analysis," J. Science Education, vol. 61(2), pp.185-199, 1977.

[21] A. Thomas, and G. Thorne, How To Increase Higher Order Thinking. Metarie, LA: Center for Development and Learning. Retrieved Dec. 7, 2009.

[22] C. Robyn, Skills for the 21st Century: Teaching higher-order thinking. This article originally appeared in the April 2014 edition of ISQ Briefings, a publication of Independent Schools Queensland. Republished with permission, 2014.

[23] D.P. Ausubel, J.D. Novak and H. Hanesian, Educational Psychology: A Cognitive View, Holt, Rhinehart and Winston, New York, 1978

[24] J.D. Novak, "Results and implications of a 12-year longitudinal study of science concept learning," Research In Science Education, vol. 35(1), pp. 23-40, 2005.

[25] J.D. Novak and A.J. Cañas, "Theoretical Origins of Concept Maps, How to Construct Them and Uses in Education," Reflecting Education, vol. 3(1), pp. 29-42, November 2007.

[26] R.M. Clary, and J.H. Wandersee, All are worthy to know the Earth: Henry De la Beche and the origin of geological literacy. Science and Education, 18 (10), pp. 1359-1376, 2009.

[27] J. Wandersee, "Using concept mapping as a knowledge mapping tool," In Fisher, K., Wandersee, J., \& Moody, D. (Eds.), Mapping biological knowledge. Dordrecht: Kluwer. pp. 127-142, 2000.

[28] Anderson and Krathwohl, Bloom's Taxonomy Revised, Understanding the New Version of Bloom's Taxonomy, A succinct discussion of the revisions of Bloom's classic cognitive taxonomy and how to use them effectively. (2001, 2005), revised 2013.

[29] C.H. Liu and R. Matthews. Vygotsky's philosophy: Constructivism and its criticisms examined. International Education Journal, 2005, 6(3), 386-399. ISSN 1443-1475 (C) 2005 Shannon Research PressPiaget, Jean." Encyclopædia Britannica. 2008. Encyclopædia Britannica Online. 3 November 2008 search.eb.com, 2005.

[30] J.E. Ormrod, Essentials of Educational Psychology: Big Ideas to Guide Effective Teaching. Boston, MA: Pearson Education Inc., 2012.

[31] M. Strautmane, "Concept map-based knowledge assessment tasks and their scoring criteria: An overview," In Concept maps: Theory, methodology, technology. Proceedings of the fifth international conference on concept mapping, vol. 2, pp. 80-88, 2012.

[32] K.M. Markam, J.J. Mintzes and M.G. Jones, "The concept map as a research and evaluation tool: Further evidence of validity," Journal of Research in Science Teaching, vol. 31(1), pp. 91-101, 1994.

[33] J.D. Novak and D.B. Gowin, Learning How to Learn. Cambridge and NY: Cambridge University Press. Also published in Spanish, Italian, Portuguese, Finnish, Arabic, Thai, Japanese, and Chinese, 1984.

[34] G. Sirhan, "Learning difficulties in chemistry: An overview," Journal of Turkish science education, vol. 4(2), pp. 2-20, September 2007.

[35] N. Nieveen, Prototyping to Reach Product Quality. in Plomp, T; Nieveen, N; Gustafson, K; Branch, R.M; and van den Akker, J (eds). Design Approaches and Tools in Education and Training. London: Kluwer Academic Publisher, 1999. 